\title{
COMENTÁRIOS SOBRE ORTOGRAFIA EM AULAS DE ALFABETIZAÇÃO
}

Lourenço Chacon*

\begin{abstract}
RESUMO: Neste artigo, discutimos como a relação criança/íngua(gem) se mostra em comentários que elas fazem em suas aulas de alfabetização. Analisamos 17 desses comentários, feitos sobre características fonético-fonológicas da língua. Dessas 17 ocorrências: (a) cinco $(29,41 \%)$ envolveram a correspondência entre segmentos da língua detectados na fala e seu registro gráfico-fonológico na escrita; (b) sete $(41,18 \%)$ fizeram alusão ao registro gráfico de características mais específicas desses segmentos; e, finalmente, (c) também cinco $(29,41 \%)$ referiram-se à estrutura da sílaba. Esses resultados (obtidos de um ponto de vista que concebe o sujeito como constituído pela e constituindo a língua) permitiram observar, por meio dos comentários, como a criança imprime esse modo de constituição da subjetividade na condução das soluções ortográficas apresentadas em seus textos.
\end{abstract}

PALAVRAS-CHAVE: Aquisição da escrita; Fonologia; Convenções ortográficas; Oralidade; Letramento.

\section{QUESTÃO}

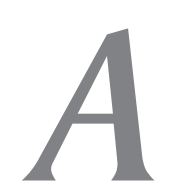

s considerações que se seguirão resultam de observações que fiz em sala de aula, bem como de encontros que tive com professoras de três Escolas Municipais de Educação Infantil (EMEIs) de Marília (SP). Resultam também de observações e de anotações do cotidiano de sala de aula feitas por pesquisadoras em nível de iniciação científica, mi-

FFC/Universidade Estadual Paulista e Programa de Pós-Graduação em Estudos Linguiísticos - Ibilce/Universidade Estadual Paulista. 
CHACON, Lourenço. Comentários sobre ortografia em aulas de alfabetização.

nhas orientandas, que desenvolveram atividades em duas dessas três escolas. ${ }^{1}$

Desse conjunto de experiências, um fato me chamou particularmente a atenção, e eu, aqui, o transformarei na questão que orientará o desenvolvimento de minhas considerações: no âmbito das práticas de letramento desenvolvidas em contexto escolar, como a relação criança/língua(gem) se mostra em comentários que elas fazem em suas aulas de alfabetização?

Como a relação criança/língua(gem) pode ser enfocada a partir de unidades de diferentes subsistemas de organização linguiística, restringirei minhas considerações a comentários nos quais essa relação diz respeito ao subsistema fonético-fonológico da língua ou, mais especificamente, aos vínculos entre esse subsistema e características ortográficas da escrita.

\section{ASPECTOS METODOLÓGICOS}

Conforme antecipei, os dados foram coletados em duas EMEIs da cidade de Marília. Em cada EMEI, uma das orientandas foi responsável pela coleta dos dados. Cada uma delas acompanhou, durante o primeiro semestre do ano de 2005, uma mesma sala de Pré III, com crianças cuja idade variou de cinco a seis anos.

1 Observações, encontros para discussões e anotações são atividades do Projeto de Extensão da FFC/Unesp Subsídios linguiístico-discursivos para o trabalho com a alfabetização. Desenvolvo-o junto a EMEIs de Marília, como fruto de atividades do Grupo de Pesquisa (CNPq) Estudos sobre a linguagem, que coordeno. As orientandas (a quem faço um agradecimento pelo apoio ao Projeto, bem como pela ajuda na seleção e na organização dos dados utilizados neste trabalho) são Daniele Maciel da Silva, Luana de Lima e Micheliny Cruz Reis, alunas do $3^{\circ}$ ano de Fonoaudiologia da FFC/Unesp. Agradeço, também, a inestimável colaboração e o apoio constante que as diretoras Dariza Aparecida Motta Fernandes, Estela Regina Crespi Toríbio e Suzi Meire de Oliveira, bem como as professoras Célia Aparecida dos Santos Carvalho e Márcia Ruiz dos Santos Silva, deram ao desenvolvimento das atividades que forneceram o material deste artigo. 
Filol. lingüíst. port., n. 8, p. 251-268, 2006.

Feita semanalmente, a coleta consistiu na anotação - na íntegra - de comentários orais que as crianças faziam sobre características da língua durante exercícios que envolviam atividades escritas. Quando um comentário motivava um par conversacional criança/professora, também foi anotada a manifestação oral da professora (resposta pontual, instrução, instigação, dentre outros tipos de manifestação). Ao anotar a fala da criança, as investigadoras descreveram também o contexto em que os comentários aconteceram, assim como características do material didático que os motivaram.

Lembro, uma vez mais, que, neste trabalho, destacarei apenas os comentários que se centraram em aspectos fonético-fonológicos da língua. No total, houve 17 comentários sobre esses aspectos.

\section{OCORRÊNCIAS}

Dessas 17 ocorrências: (a) 5 (29,41\%) envolveram a correspondência entre segmentos da língua detectados na fala e seu registro gráfico-fonológico na escrita; (b) 7 (41,18\%), o registro gráfico de características perceptuais desses segmentos; e, finalmente, (c) também 5 (29,41\%), a estrutura da sílaba.

Faço, aqui, uma observação: preferi falar em segmentos da fala (e não em fonemas), para o caso (a), e em características de segmentos (e não em características ou traços de fonemas), para o caso (b), por entender que as crianças em processo de alfabetização levam, para sua escrita, informações linguiísticas que detectam, em termos físicos - entenda-se: motores, acústicos e gráficos -, nos enunciados falados e escritos que produzem e com os quais convivem em situações de oralidade e de letramento. Enfatizo esse aspecto físico inspirado em Câmara Jr. Com efeito, para esse linguiista, na oscilação possível entre, por um lado, [i] e [e] em "passear" e, por outro, [u] e [o] em "voar", atua, além de uma oscilação "entre duas pautas vocálicas" (respectivamente, "na fala coloquial espontâ- 
CHACON, Lourenço. Comentários sobre ortografia em aulas de alfabetização.

nea" e "num uso formal, consciente"), ainda "a imagem das letras $e$ e $o$ da grafia." (Câmara Jr., 1976, p. 21-2). ${ }^{2}$

O quadro que se segue sintetiza as ocorrências obtidas:

\begin{tabular}{|c|c|c|c|}
\hline & $\begin{array}{c}\text { (a) Correspondência } \\
\text { segmentos/grafemas }\end{array}$ & $\begin{array}{c}\text { (b) Características } \\
\text { perceptuais de segmentos }\end{array}$ & $\begin{array}{c}\text { (c) Estrutura da } \\
\text { sílaba }\end{array}$ \\
\hline Subtotal: & $5(29,41 \%)$ & $7(41,18 \%)$ & $5(29,41 \%)$ \\
\hline TOTAL: & \multicolumn{3}{|c}{$17(100 \%)$} \\
\hline
\end{tabular}

Quadro 1 - Relação entre comentários e aspectos fonético-fonológicos da língua

Passaremos à exposição de ocorrências de cada tipo de comentário encontrado.

\section{A) CORRESPONDÊNCIA SEGMENTOS/GRAFEMAS}

\section{Uma primeira ocorrência é a seguinte:}

(1) A professora (P) estava escrevendo a palavra "pirulito" na lousa e perguntou:

P: Como escreve o "li"?

Um aluno $(\mathrm{A})$ respondeu:

2 Essa oscilação entre o que Câmara Jr. entende como pautas vocálicas e a imagem das letras e da grafia pode ser detectada já desde as primeiras manifestações de escrita alfabética de crianças. Em Chacon (2006), destaco a grafia "eo" para "eu" na escrita de uma criança de educação infantil de nível III (seis anos). O registro com "o" e não com "u" mostra indícios de um conhecimento, por parte da criança, de que muitas vezes o que se percebe, na fala, como [u] é grafado com "o". Portanto, uma combinação entrecaracterísticas acústicas de um som e diferentes possibilidades de registro ortográfico desse som deve ter levado a criança, no caso em destaque, a grafar com "o" aquilo que deveria ser escrito com "u" -já que, em outras situações, como em "carro", por exemplo, a vogal átona final é grafada com "o". Ou seja, nas palavras de Corrêa (2001, p. 142), "é sempre o produto do trânsito entre práticas sociais orais/faladas e letradas/escritas que nos chega como material de análise do modo de enunciação falado e do modo de enunciação escrito" (destaque meu). 
A: É o /r/ e o /1/.

$\mathrm{P}$ : Você tem certeza? - perguntou $\mathrm{P}$.

$\mathrm{O}$ aluno pensa por um instante e logo se corrige: A: É o /1/ e o "i”.

Estamos, nessa ocorrência, diante de uma situação que envolve a relação muito próxima entre dois fonemas da língua: / / / e /1/. Trata-se de fonemas que, de acordo com Chomsky \& Halle (1991), teriam em comum os traços <+soante; -vocálico; + consonantal; + coronal; + anterior $>$, características que os aproximam em termos motores e acústicos, na fala. Além dessa aproximação, no português do Brasil, /r/ e // se aproximam também por sua distribuição, já que ambos podem ocorrer no ataque simples de sílabas internas à palavra (como em "cara" e "cala"), bem como na segunda posição de um ataque ramificado (como em "crave" - do verbo "cravar" - e "clave"). No caso da resposta da criança, deve-se ainda levar em consideração que os dois fonemas ocorrem na palavra "pirulito”. Finalmente, seria importante lembrar que a oposição entre esses fonemas, em certas variações de caráter diacrônico ou sincrônico do português, muitas vezes se neutraliza (como se pode depreender da não-distinção entre "globo" e "grobo", que, sincronicamente, marca uma variação social característica de variedades não-padrão). Como se vê, esse conjunto de fatores torna não-casual a dúvida da criança, já que se trata da percepção de uma regularidade da própria língua.

Vamos a uma outra ocorrência que envolve a correspondência segmentos/grafemas:

(2) Um aluno $\left(A_{1}\right)$ foi escrever a palavra "laranja" na lousa, sem conseguir. A professora pede, então, auxílio à classe. Depois de escrever "laran", perguntou:

P: Classe, como eu escrevo "ja”?

Um outro aluno $\left(A_{2}\right)$ respondeu:

$\mathrm{A}_{2}$ : É o "g" e o "a". 
A professora escreveu tal como $\mathrm{A}_{2}$ sugeriu. Ao ver na lousa a escrita sugerida por $A_{2}$, imediatamente $A_{1}$ disse:

$\mathrm{A}_{1}$ : Isso é o "ga".

Percebendo o erro, vários alunos $\left(A_{C}\right)$ disseram em coro: $A_{c}$ : É o "j” e o "a”.

Nessa ocorrência, está mais diretamente em questão a correspondência entre um fonema específico /3/ e duas possibilidades ortográficas de seu registro em nossa escrita, a saber, com os grafemas "g" e "j". Além dessa correspondência não-unívoca, a similaridade acústica entre o nome falado de um dos grafemas que podem corresponder ao fonema /3/, a saber, a "letra GE" (tal como designada na tradição escolar), e a realização desse fonema na fala pode também ter levado $A_{2}$ a enunciar "g" como resposta à professora.

Destaque deve ser feito à observação de $A_{1}$ e, sobretudo, à resposta de vários alunos $\left(\mathrm{A}_{C}\right)$ da sala: observação e resposta indiciam alguma forma de conhecimento, por parte desses alunos, de que os valores fonológicos que podem ser atribuídos aos grafemas dependem, em alguns casos, do contexto em que os grafemas ocorrem. Em alguma medida, pois, a resposta de vários alunos da sala remete à percepção do que Scliar-Cabral (2003) categoriza como valor de um grafema dependente de seu contexto escrito, a saber: o grafema "g", diante dos grafemas "a", "o" e "u" não corresponde ao fonema /3/.

Passemos a outra ocorrência:

(3) Um aluno, ao escrever no caderno a palavra "bateu", se questionou:

A: "Bateu" é com "l" ou "u"?

Depois de refletir um pouco, disse:

A: Ah, é claro que é com "u”.

Não se trata de uma dúvida banal: do ponto de vista fonéticofonológico, “(...) em muitas falas populares, /// não figura (...) na sua variante velar, mas é substituído por um /u/ como vogal auxiliar de 256 
ditongo" (Câmara Jr., 1976, p. 18). É justamente o caso da variedade linguíística das crianças deste estudo. No entanto, de um ponto de vista morfológico, mais uma vez, estaria em questão o valor contextual que se pode atribuir a um grafema da língua, embora, desta feita, não dependente do contexto escrito. Futuramente, em suas aulas de língua portuguesa, essa criança aprenderá que a terminação verbal na terceira pessoa do singular de verbos regulares se escreve com o grafema "u" e não com o grafema "l”. A propósito, talvez a expressão é claro que do enunciado da criança indique, já nesse momento inicial de seu contato formal com a escrita, um saber intuitivo sobre aspectos morfológicos das palavras e seu registro gráfico na escrita.

Vamos a uma última ocorrência de comentários que envolvem correspondências segmentos/grafemas:

(4) Ao escrever a palavra "televisão", um aluno (A) pergunta:

A: Professora, como escreve o "são"?

A professora o questiona:

P: Como você acha?

Nova pergunta:

A: É o "z" e o "ão"?

A professora responde:

$P:$ Tem som de " $z$ ", mas se escreve com "s".

Ele reflete (em voz alta):

A: O "s" e o "ão"...

Nesta ocorrência, mais uma vez, os diferentes valores fonológicos dos grafemas da língua suscitam a dúvida na criança. No entanto, nem o contexto gráfico - como em (2) - nem o contexto morfológico - como em (3) - dariam os elementos necessários à criança para prever qual dos dois grafemas em concorrência deve figurar na palavra em questão.

Em síntese, nos casos de (1) a (4), pudemos verificar que os comentários das crianças indiciam diferentes graus (ou nuances) de 
dificuldades relacionadas à correspondência segmentos/grafemas. Com efeito, os comentários mobilizaram: segmentos contrastivos com distribuição muito próxima na língua, como em (1); aspectos contextuais de grafemas, que favorecem sua previsão na escrita tanto em razão de aspectos relacionados às convenções ortográficas, como em (2), quanto em razão de características morfológicas de palavras em que ocorrem, como em (3); e, por fim, situações em que o contexto não favorece a escolha de grafemas que competem entre si em determinados pontos da cadeia escrita, como em (4).

Passemos a outra ordem de comentários.

\section{B) CARACTERÍSTICAS PERCEPTUAIS DE SEGMENTOS}

Duas características foram realçadas nos comentários, as quais serão exemplificadas nas ocorrências (5), (6) e (7). Vejamos a primeira delas:

(5) Um aluno $\left(A_{1}\right)$ foi escrever a palavra "limão" na lousa. Com o auxílio dos colegas e da professora, escreveu "limao". Dirigindose a todos, a professora perguntou:

P: Está certo, classe?

Um outro aluno $\left(\mathrm{A}_{2}\right)$ respondeu:

$A_{2}$ : Não, falta um negócio lá em cima.

Rindo, a professora disse:

P: Muito bem, $A_{2}$, falta o til.

Como se vê, o comentário da criança envolve "uma nasalação que se opõe distintamente à não-nasalação" (Câmara Jr, 1976, p. 25), como a que distinguiria "pão" e "pau”. Destaque-se, no entanto, que, para esse autor:

A nasalidade pura da vogal não existe (...) fonologicamente, porque por meio dela não se cria contraste distintivo com a vogal travada por consoante nasal. A situação em português, nesse particular, é diversa do francês, onde 
Filol. lingüíst. port., n. 8, p. 251-268, 2006.

uma vogal puramente nasal como em /bõ/, escrito bon, opõe-se ao fechamento consonântico de /bon/, escrito bonne, na relação de masculino para feminino. (op. cit., p. 31)

Assim, o que, na fala, se perceberia como uma vogal nasal deve ser entendido, em termos fonológicos, "como um grupo de dois fonemas que se combinam na sílaba: vogal e elemento nasal" (op. cit, p. 25). Em termos fonéticos, porém, as marcas desse elemento fonológico nasal localizado na coda silábica criam uma "chamada vogal nasal (como em lã, campo ou lenço)" (op. cit., p. 18). Ou seja, embora, de acordo com esse autor, do sistema fonológico do português não façam parte vogais propriamente nasais, na produção da fala, características acústicas da nasalidade fonológica da coda silábica tornam-se bastante perceptíveis na vogal que está no núcleo da sílaba. E é a percepção do elemento fonológico nasal localizado na coda (responsável por passar suas características para a vogal que o antecede) que nos parece estar em questão no comentário da criança em (5).

Mas não apenas características acústicas da nasalidade fonológica são salientes às crianças, como nos mostra a ocorrência seguinte, em que um outro tipo de nasalidade está em questão:

(6) A professora (P) estava ditando a frase "A boneca é de pano". Ao ditar a palavra "pano", um aluno $\left(A_{1}\right)$ perguntou:

$\mathrm{A}_{1}$ : É o "p", professora?

Um outro aluno $\left(A_{2}\right)$ respondeu:

$A_{2}$ : O "p", o "a" e o tilzinho, "pã".

Obs.: Muitos alunos escreveram "pãno".

Segundo Câmara Jr. (1976), “(...) o português, ao lado da nasalidade fonológica, também tem essa nasalidade ocorrente por assimilação à consoante nasal de uma sílaba seguinte" (op. cit., p. 25). Trata-se, em (6), da percepção de um tipo de nasalidade resultante do fato de que "(...) o falante tende a antecipar o abaixamento do véu palatino, necessário à emissão nasal da consoante na 
sílaba seguinte, e emite já nasalada a vogal precedente" (op. cit., p. 25). Assim, em (6) e em (5), estão, respectivamente, em questão percepções de "uma possível nasalação, que é meramente mecânica e fonética (sem efeito para distinguir formas da língua) e [de] uma nasalação que se opõe distintamente à não-nasalação" (id. ibid). Em outras palavras, os comentários das crianças remetem à percepção e ao registro da nasalidade em "(...) vogais que são nasais em termos fonêmicos”, em (5), e à percepção - mais fina - da nasalidade naqueles casos em que nem sempre seu registro gráfico é necessário, como em (6), nos quais “(...) o que a fonética apurada registra é uma leve nasalação de uma vogal em contacto com uma consoante nasal da sílaba seguinte, no mesmo vocábulo" (op. cit., p. 24-5).

Vale ressaltar que, além da percepção da nasalidade (tanto daquela fonêmica, "que se opõe distintamente à não-nasalação", quanto daquela "meramente mecânica e fonética"), a utilização de um diacrítico específico para marcá-la na escrita - muitas vezes, no caso fonêmico, o til, como em "irmã" ou "ladrão"; e, algumas vezes, no caso fonético, o acento circunflexo, como em "lâmpada" - frequientemente a torna bastante saliente para crianças em processo de alfabetização.

Passemos à segunda ocorrência de comentários sobre características de segmentos:

(7) Ao nomear figuras de uma atividade que vinha desenvolvendo, um aluno $(A)$ perguntou:

A: "Vela" também tem aquele assim, ó? (desenhando no ar o acento agudo com o dedo).

Obs: Um pouco antes, havia escrito "boné" e colocado acento agudo.

Como resposta, ouviu da professora $(\mathrm{P})$ :

P: Escreve do jeito que você acha que é.

$\mathrm{O}$ aluno optou por colocar o acento. 
Filol. lingüíst. port., n. 8, p. 251-268, 2006.

Nesse caso, além de manifestar a percepção dos vínculos entre características motoras (grau de abertura) e acústicas (relação entre formantes, sobretudo aquela entre F1 e F2) que diferenciam as vogais anteriores médias, o comentário parece indiciar a intuição da criança de que não há um registro gráfico único para essas características diferenciais de vogais médias. Desse modo, a dúvida da criança sobre diferentes possibilidades gráficas de registro dessas características acústicas apontaria, ao mesmo tempo: (1) para uma possível percepção de características rítmicas da língua (a palavra "boné", escrita pouco antes da enunciação da dúvida, calca-se num pé iambo; a palavra "vela", num pé troqueu) e, provavelmente, para o caráter marcado das oxítonas do português brasileiro (em relação ao não-marcado, a saber, o das paroxítonas); e (2) para princípios de nosso sistema ortográfico, atento às diferenças marcado/ não-marcado da posição do acento no português brasileiro. Com efeito,

\begin{abstract}
A forma padrão do vocábulo da língua portuguesa, quanto ao acento de intensidade, é o vocábulo paroxítono, por isto, estes vocábulos, só mediante certas condições ${ }^{3}$ recebem o acento gráfico, pois os codificadores da ortografia do português procuraram evitar o uso do acento gráfico, sempre que possível. (Scliar-Cabral, 2003, p. 65-6 - destaque da autora)
\end{abstract}

Assim, mesmo que tenha optado por colocar acento agudo em $[\varepsilon]$ na palavra "vela", ou seja, mesmo que tenha optado por marcar as características acústicas dessa vogal na escrita contrariando os princípios ortográficos do português brasileiro, a dúvida sobre colocar, ou não, esse acento gráfico, de algum modo, parece calcarse em alguma intuição, por parte da criança, de que seu registro (ou

3 A condição principal é a de a última sílaba da paroxítona ser pesada, ou seja, em termos de Câmara Jr. (1976, p. 26), ser uma sílaba "fechada" ou "travada". Essa condição aponta para o caráter marcado desse tipo de paroxítona do português brasileiro. A propósito, Collischon (1996), referindo-se a levantamento feito, no Dicionário Delta Larousse, por Leda Bisol, destaca que " $78 \%$ das palavras terminadas em consoante eram oxítonas, ao passo que apenas $22 \%$ eram paroxítonas” (op. cit., p. 140). 
não) na escrita deve-se, sobretudo, a diferenças de distribuição (probabilística) das estruturas rítmicas da língua.

Retomando as ocorrências (5), (6) e (7), vimos que os comentários nelas expostos remetem à relação entre o que nos parecem ser características especiais detectáveis, pelas crianças, em segmentos da língua (como a nasalidade e o grau de abertura vocálica) e seu registro gráfico. No entanto, se, por um lado, em (5) e em (6), o comentário sobre o diacrítico envolve (talvez mais especificamente) o que, para a criança, seria uma característica acústico-perceptual localizável num segmento, em (6), não é apenas isso que ocorre. Como vimos, embora a solução da criança tenha apontado para o privilégio a uma característica acústico-perceptual, fatores fonológicos de outra ordem (a do ritmo) provavelmente tenham mobilizado a dúvida que manifestou sobre a palavra "vela" ter, ou não ter, acento gráfico. Portanto, esses comentários remetem ao próprio estatuto dos diacríticos: assinalar características de segmentos ou assinalar características rítmicas da língua? Ou, em outras palavras, remetem ao estatuto daquilo que, para as crianças, faz parte da escrita - um negócio lá em cima [em (5)] e aquele assim, ó [em (6)] - mas não são grafemas.

Passemos, finalmente, às nossas últimas ocorrências:

\section{(C) ESTRUTURA DA SÍLABA NA ESCRITA}

Em razão da importância que nos parecem ter não só para a reflexão sobre a aquisição da escrita mas também para as próprias teorias fonológicas, daremos destaque àquelas ocorrências que problematizam a complexidade dos padrões silábicos:

(8) A professora (P) pediu para que os alunos a ajudassem a escrever a palavra "presente". Logo, alguns alunos $\left(A_{C}\right)$ responderam:

$$
A_{C}: O \text { "e”. }
$$


Filol. lingüíst. port., n. 8, p. 251-268, 2006.

Após escrever o grafema mencionado na lousa, $\mathrm{P}$ perguntou: P: O que está faltando?

Um aluno $\left(A_{1}\right)$ respondeu:

$\mathrm{A}_{1}$ : O de "professora" - referindo-se ao encontro "pr".

A professora escreveu a sequiência na lousa, dando-lhe parabéns.

Chama a atenção nessa ocorrência não apenas a facilidade com que as crianças detectam o ápice da sílaba (no português brasileiro, sempre preenchido por uma vogal), mas também a não-facilidade das crianças com a detecção do que preenche as encostas da sílaba (em geral, consoantes). Fatores de natureza perceptual certamente estão na base tanto dessa facilidade quanto dessa não-facilidade. Com efeito, "sob o aspecto fonético, o ápice usualmente excede as encostas em intensidade e em muitos casos evidencia um acréscimo de frequiência básica. Perceptualmente, o ápice se distingue das encostas por um maior vigor (...) de voz (...)" (Jakobson, 1978, p. 69).

Assim, o menor "vigor" das encostas as tornaria, naturalmente, menos audíveis, resultando em menor propensão a serem registradas na escrita. Essa menor propensão se acentuaria nos casos em que uma encosta é preenchida por mais de um segmento consonantal, como acontece na ocorrência em destaque. Embora seja previsto pela estrutura fonológica do português, esse padrão não é tão recorrente quanto o padrão $\mathrm{CV}$, de natureza universal, ${ }^{4}$ já que "numa língua de maior variedade de tipos silábicos, a recorrência de uma classe de fonema oferece graus diversos de probabilidade" (Jakobson, id. ibid).

Confirma esse caráter probabilístico o comentário a seguir, no qual estão em questão a busca (ou eficácia) desse padrão univer-

Segundo Jakobson (1978, p. 69), "há línguas em que toda sílaba consiste de uma consoante e uma vogal seguinte (...)". 
sal e a pouca produtividade linguiística de padrões silábicos mais complexos, sobretudo no léxico infantil:

(9) A professora entregou embalagens de creme dental e de sabonete para os alunos lerem o nome dos produtos. Uma aluna $\left(A_{1}\right)$ que estava com a embalagem do creme dental SORRISO viu escrito no cantinho da embalagem a expressão "Tripla refrescância", lendo em voz alta:

\section{$\mathrm{A}_{1}$ : "Terrípela".}

Ao ouvir a leitura da colega, outra aluna $\left(A_{2}\right)$ corrigiu-a:

$A_{2}$ : Não é "terrípela" é "tripla", "tripla".

Como se pode observar, só a tendência - bastante comum em iniciantes da escrita - de usar o nome de alguns grafemas (como, no caso, o "t" e o "p") para escrever e ler sílabas de palavras não parece explicar a base da leitura de $A_{1}$. Sua leitura também parece indicar a preferência e a produtividade (não apenas do português, mas universal) do padrão silábico CV e o caráter marcado do padrão CCV - mais marcado ainda na palavra "tripla" pelo fato de estar presente em ambas as sílabas da palavra.

Obviamente, outros fatores podem, ainda, ter contribuído para a ocorrência dos comentários (8) e (9) a respeito da complexidade da sílaba na escrita. A própria aquisição mais tardia (na fala) de padrões como CCV, por um lado, e a apresentação didática das famílias silábicas mais simples (do tipo CV) antes das mais complexas (outros tipos silábicos ou estruturas com dígrafos) nas práticas de alfabetização, por outro, acabam por criar, nas crianças, a percepção daquilo que é não-marcado e daquilo que é marcado na estrutura da sílaba (bem como em outros processos fonológicos envolvidos na escrita, como vimos em exemplos anteriores).

$\mathrm{O}$ que nos suscitam as questões de que tratamos nas nove ocorrências que destacamos? Veremos a seguir. 
Filol. lingüíst. port., n. 8, p. 251-268, 2006.

\section{PARA REFLEXÃO}

No que diz respeito à criança, seus momentos de dúvida, a nosso ver, mostram que ela, “(...) enquanto sujeito falante, se dividiria entre aquele que fala e aquele que escuta sua própria fala, sendo capaz de retomá-la, reformulá-la e reconhecer a diferença entre sua fala e a fala do outro, assim como entre a instância subjetiva que fala e a instância subjetiva que escuta de um lugar outro" (De Lemos, 2002, p. 56). Acrescentaríamos, em nosso caso, que essa criança é ao mesmo tempo falante/escrevente e ouvinte/leitor. Assim, é no entrecruzamento entre práticas orais e práticas letradas que os comentários falados apontam para o reconhecimento da diferença entre uma e outra possibilidade (ao mesmo tempo, acústica e visual) com que a escrita se faz ouvir/ver "de um lugar outro", tanto nos momentos que se podem chamar de autocorreção (por exemplo: "Bateu" é com "l" ou "u"? (...) Ah, é claro que é com "u") quanto naqueles em que a correção vem de um outro sujeito (o professor ou uma outra criança; por exemplo: Não é "terrípela" é "tripla", "tripla"), também ele afetado pelo audição e pela visão da escrita/leitura de seu aluno ou colega de sala.

Desse modo, os comentários mostram sempre “(...) um sujeito que, ao se constituir na língua, por ela é dividido (...)” (op. cit., p. 56). Em outras palavras, cada momento de estranhamento aponta "para a emergência de um sujeito em outro intervalo: naquele que se abre entre a instância que [fala/escreve] e a instância que [escuta/ lê], instâncias não coincidentes (...)" (idem, p. 62).

No entanto, se nos chamam a atenção os efeitos dessa nãocoincidência de instâncias nas oscilações da criança, chama-nos igualmente a atenção o fato de que oscilações, a despeito de seu caráter convencional, são constitutivas do próprio sistema de escrita com o qual a criança está às voltas. Esses momentos iniciais do contato escolar da criança com a escrita são, portanto, momentos nos quais, de modo privilegiado, tanto se mostra o caráter heterogêneo da escrita quanto a constituição do sujeito escrevente (de modo estrito) e a aquisição da linguagem (de modo amplo). 
CHACON, Lourenço. Comentários sobre ortografia em aulas de alfabetização.

E é justamente com essa heterogeneidade (da escrita) e com essa constituição (do sujeito escrevente em aquisição de linguagem) que o professor alfabetizador vai lidar - como um "outro preferencial” no processo de alfabetização. Sobretudo quando instiga, ele é muitas vezes o elemento que faz ressoar nas crianças a heterogeneidade com a qual elas já estão às voltas (também) na atividade da escrita. Destaquemos, a título de exemplo, enunciados do alfabetizador que demonstram essa nossa afirmação: Você tem certeza? em (1); Como você acha? em (4); Está certo, classe? em (5); Escreve do jeito que você acha que é em (7); 0 que está faltando? em (8).

Mas, ao mesmo tempo, o alfabetizador é o elemento que também pode ressoar nas crianças suas próprias tentativas de (suposto) controle dessa heterogeneidade, tentativa necessária quando se pensa no caráter convencional do sistema de escrita, com o qual as crianças estão às voltas ao se "escutarem/lerem" de um outro lugar: Tem som de " $z$ ", mas se escreve com "s" em (4); Muito bem, $A_{2}$, falta o til em (5).

Vale a pena lembrar, porém, que as contribuições advindas das teorias da linguagem e, neste estudo, em particular, das teorias da aquisição da escrita, não podem ser usadas como instrumento para se atribuir culpa aos agentes de alfabetização.

Pensando na complexidade do papel do alfabetizador e, sobretudo, no reconhecimento da importância desse papel tanto por parte do próprio alfabetizador quanto por parte dos demais atores envolvidos na prática da alfabetização, levantaremos algumas questões, relacionadas ao acompanhamento do aluno e à formação do professor:

(1) estariam os alfabetizadores mais atentos ao modo como as crianças formam um imaginário sobre a escrita, ou ao modo como eles acham mais legítimo desenvolver o trabalho com as convenções ortográficas?;

(2) teriam sido os próprios alfabetizadores, assim como ocorre com as crianças, sensibilizados às características fonológicas da língua e 
Filol. lingüíst. port., n. 8, p. 251-268, 2006.

manifestariam eles, de modo sistemático, essa sensibilidade quando desenvolvem seu trabalho em sala de aula?;

(3) teriam sido contemplados os alfabetizadores, em sua formação, com saberes sobre a complexidade das convenções ortográficas, bem como de sua base linguíística?;

(4) teriam sido sensibilizados os alfabetizadores para assumirem a tarefa de trabalhar com as percepções da criança sobre a função social da escrita, isto é, para lidarem com a maneira pela qual os diferentes modos de organização da língua se mostram nas diferentes práticas de linguagem (orais e letradas)?

Sem dúvida alguma, há exemplos de atitudes de alfabetizadores - e os dados de nosso Projeto de Extensão as mostram - que assinalam, neles, o reconhecimento da importância de seu papel tal como o concebemos, ou seja, de, ao mesmo tempo, mostrar (como um "outro preferencial”) a heterogeneidade da escrita mas também suas tentativas de controle - aliás, muitas vezes já pressentidas pelas próprias crianças! Mas, para que os alfabetizadores desempenhem com mais eficácia esse seu papel, e como as práticas letradas desenvolvem-se sob base (também) linguiística, acreditamos serem necessários muito mais investimentos nos cursos que os habilitam para a profissão, tanto no que se refere a saberes (não-intuitivos) sobre princípios de organização linguiística, quanto no que se refere a saberes (também não-intuitivos) sobre a aquisição da linguagem (de modo geral) e sobre a aquisição da escrita (de modo mais específico) - saberes, até onde vai o nosso próprio conhecimento sobre a formação de alfabetizadores, ainda muito pouco contemplados nessa formação.

\section{BIBLIOGRAFIA}

CÂMARA JR., J. M. (1976). Problemas de lingüística descritiva. 7. ed. Petrópolis: Vozes.

CHACON, L. (2006) Marcas de coda silábica na escrita infantil. Texto apresentado em mesaredonda no VII Encontro do CELSUL. Pelotas (inédito). 
CHACON, Lourenço. Comentários sobre ortografia em aulas de alfabetização.

CHOMSKY, N. \& HALLE, M (1991). The phonetic framework. In: Sound patterns of English. 2. ed. Cambridge/London: The MIT Press.

COLLISCHON, G. (1996). O acento em português. In: BISOL, L. (Org.) Introdução a estudos de fonologia do português brasileiro. Porto Alegre: EDIPUCRS; p. 131-159.

CORRÊA, M.L.G. (2001). Letramento e heterogeneidade da escrita no ensino de Português. In: SIGNORINI, I. (Org.). Investigando a relação oral/escrito e as teorias do letramento. São Paulo: Mercado de Letras.

DE LEMOS, C.T.G. (2002). Das vicissitudes da fala da criança e de sua investigação. Cadernos de estudos lingüísticos, 42, p. 41-70.

JAKOBSON, R. (1978) Fonema e Fonologia. In: SAUSSURE, F. et al. Textos selecionados. 2. ed. São Paulo: Abril Cultural.

SCLIAR-CABRAL, L. (2003). Guia prático de alfabetização. São Paulo: Contexto.

ABSTRACT: This paper discusses how the relationship between child and language can be evidenced by the comments that children make during their literacy classes. Seventeen comments about phonetic-phonological traits of the language are analyzed. Among them, $05(29,41 \%)$ involve the correspondence between speech segments and graphemes; 07 seven $(41,18 \%)$ allude to more specific traits of these segments; and $05(29,41 \%)$ refer to syllable structure. From the viewpoint of an approach that conceives subjectivity as constituted by language, our results show how children, by means of their comments, impose this constitution in the way they deal with orthography.

KEYWORDS: Writing acquisition; Phonology; Orthography; Orality; Literacy. 